\title{
An Electron Microscope Study of Root-Hair Infection by Rhizobium
}

\author{
By KARIN SAHLMAN AND G. FÅHRAEUS \\ Department of Microbiology, Royal Agricultural College, Uppsala 7, Sweden
}

(Received 10 June 1963)

\begin{abstract}
SUMMARY
Root hairs of clover seedlings infected by Rhizobium were studied in the electron microscope. The appearance of the infection sites supports the invagination hypothesis proposed by Nutman. The origin of the material enclosing the bacteria within the infection thread is discussed.
\end{abstract}

\section{INTRODUC'TION}

In 1956, Nutman launched the idea of root-hair invagination as a mechanism for the rhizobial infection of leguminous plants. This hypothesis was founded mainly on negative evidence: no enzymic or physical penetration of the root-hair wall by the bacteria had ever been observed. Later investigations (Fåhraeus \& Ljunggren, 1959) seemed to show that the enzyme polygalacturonase (PG) actually plays a part in the infection, but this does not necessarily mean that the cell wall becomes penetrated; PG may also take part in an invagination process (Ljunggren \& Fåhraeus, 1961).

Direct evidence for such a mechanism has so far been lacking. In an electron microscopic study of soybean root-nodules Bergersen \& Briggs (1958) observed bacteroids surrounded by membrane systems that were thought to be continuous with the host cell membrane, but no micrograph was presented to illustrate this. The findings were, however, interpreted as giving support to Nutman's hypothesis.

We have tried to get more direct proof by studying the sites of infection on the root hairs in the electron microscope. This would seem to be an extremely difficult task because of the well-known scarcity of infected root hairs in most leguminous plants. However, by means of a slight modification of the slide technique for growing clover seedlings (Fåhraeus, 1957) it was possible to locate the infection threads accurately enough for successful sectioning, and a number of electron micrographs of infected root hairs have been obtained.

\section{METHODS}

The great difficulty in this work was to find infection threads and to carry them through all the stages of preparation. A suitable material is Trifolium parviflorum Ehrh.; this species forms a great number of infection threads, and it was used for all studies of root hairs. The technique was based on the earlier method for cultivating seedlings on glass slides (Fåhraeus, 1957). As suggested by Nutman (1959), a small chamber was built of glass spacers and araldite; we used small squares cut from ordinary microscope slides making a chamber $0.9 \mathrm{~mm}$. in thickness. This was filled 
with mineral solution (Fåhraeus, 1957, without agar), and the roots of 2-day-old seedlings were gently pushed into it. The slides were kept in wide culture tubes with the same medium and the plants were allowed to grow for about 1 week. When the first nodules appeared, the roots were scanned under the microscope, and the slides showing the largest number of infections selected and placed on bent glass rods in Petri dishes. The solution was drained off with filter paper and replaced by fixation fluid (osmic acid in Palade's buffer solution). In the same way the roots were washed and dehydrated in alcohol and finally embedded in methacrylate with catalyst, the plants being dislocated as little as possible during this procedure. The slides were examined under the microscope after which the cover slip was removed, and small pieces of roots bearing infected hairs were cut out with a razor blade and placed in gelatin capsules containing methacrylate with catalyst.

The trimming of the hardened blocks was done under a dissecting microscope with transmitted light, which was necessary to make the root hairs clearly visible. During the trimming and subsequent sectioning the blocks were continuously checked under an ordinary microscope at a magnification of $70 \times$. Sections were cut on a Philips ultramicrotome, mounted on formvar films and photographed in a RCA EMU $3 b$ microscope using Gevaert Litholine Ortho glass plates.

\section{RESULTS AND DISCUSSION}

Two micrographs showing sectioned root hairs will be seen in Pl. 1. Figure 1 shows a typical 'curled' hair with the origin of an infection thread. As often observed in the light microscope there was a considerable amount of 'bacterial tissue' just at the entrance point (compare Fåhraeus, 1957, Pl. 2, fig. 9). It is well known that the infection thread is not always straight and smooth but is somewhat contorted and often looks rugged with several small extensions. In ultra-thin sections the infection thread will therefore appear as a series of separated and irregular areas of cell wall substance enclosing bacteria.

In Pl. 1, fig. 2, the site of entry is seen as a narrow channel whose walls are entirely continuous with the hair wall. The channel ends in a typical infection thread containing two bacteria. In our opinion this picture provides good evidence for the validity of the invagination hypothesis. Serial sections of a number of root hairs failed to show any breaks in the root hair wall connecting the infection threads with the external solution.

Some further details in the micrographs should be pointed out here. Most bacteria are surrounded by transparent zones. This might be due in part to a slight shrinkage of the bacteria during the preparation, or they may represent bacterial capsules. A denser material enclosing the bacteria is particularly evident in Pl. 1, fig. 2; it is also seen very clearly in sections of young nodules (Pl. 1, fig. 3). This material is most probably of plant origin. It could perhaps be identical with the 'mucilaginous sheath' or the cuticle covering the root epidermis and the surface of root hairs in several plants, as described by Scott et al. (1958). The material seems to be very fragile and is not easily observed on the outer root hair surface, but might be protected in the hair folds containing the bacteria. It could be responsible for the strong adhesion of many bacterial rods to the cell surface as seen in Pl. 1, fig. 1. It is noteworthy that all bacteria are attached only at the end, which seems to imply a polarly located site of affinity to the root hair surface. 
Journal of General Microbiology, Vol. 33, No. 3

Plate 1
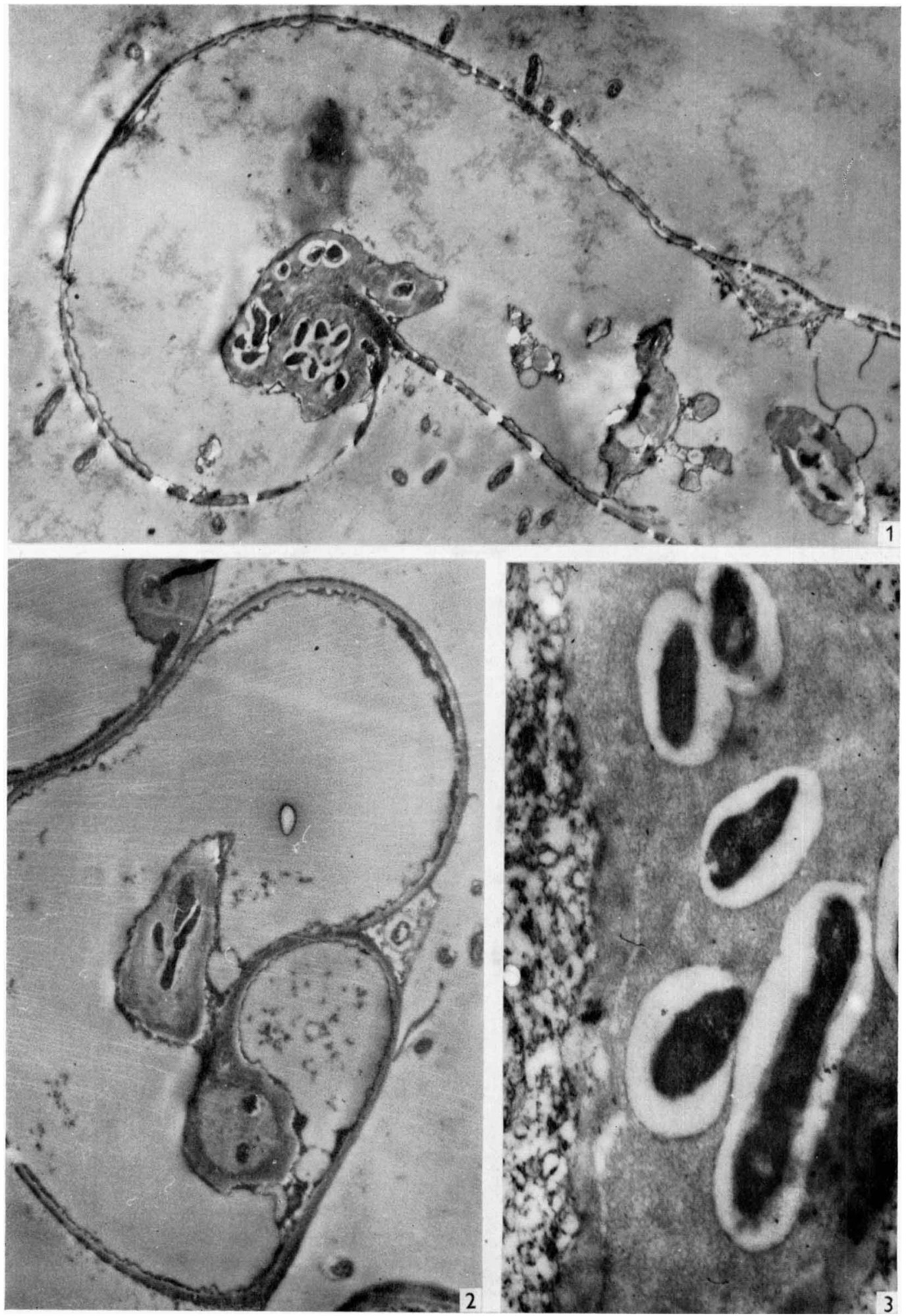

K. SAHLMAN AND G. FÄHRAEUS

(Facing p. 427) 
We thank Drs P.S. Nutman and Barbara Mosse for valuable discussions and for the seed material of Trifolium parviflorum.

\section{REFERENCES}

Brrgersen, F. J. \& Briggs, M. J. (1958). Studies on the bacterial component of soybean root nodules: cytology and organization in the host tissue. J. gen. Microbiol. 19, 482.

FAnraeus, G. (1957). The infection of clover root hairs by nodule bacteria studied by a simple glass slide technique. J. gen. Microbiol. 16, 374.

Fåmraeus, G. \& LuUngGren, H. (1959). The possible significance of pectic enzymes in root hair infection by nodule bacteria. Physiol. Plant. 12, 145.

LJUNGGREN, H. \& FÅHRAEUS, G. (1961). The role of polygalacturonase in root-hair invasion by nodule bacteria. J. gen. Microbiol. 26, 521 .

Nutman, P. S. (1956). The influence of the legume in root-nodule symbiosis. Biol. Rev. 31, 109.

Nutman, P.S. (1959). Some observations on root-hair infection by nodule bacteria. J. exp. Bot. 10, 250.

Scott, F. M., Hamner, K. C., Baker, E. \& Bowler, E. (1958). Electron microscope studies of the epidermis of Allium cepa. Amer, J. Bot. 45, 449.

\section{EXPLANATION OF PLATE}

Fig. 1. Longitudinal section through an infected root hair of Trifolium parviflorum showing the beginning of an infection thread in the fold of the curled hair tip. Some more parts of the thread are seen nearer the base of the hair. Magnification $\times \mathbf{5 5 0 0}$.

Fig. 2. Oblique section through the tip of an infected root hair of Trifolium parviflorum. In the middle there are two parts of an infection thread. The wall of the lower one is continuous with the root hair wall. In the upper left corner there is another root hair containing an infection thread. Magnification $\times 7000$.

Fig. 3. Section through a part of a cell of a young nodule of Trifolium repens showing an infection thread in longitudinal section. Bacteroids had not yet developed in this cell. The light areas surrounding the bacteria are probably capsules. Note the boundary between the more granular material around the bacteria and the thread wall. On the left is the cytoplasm of the host cell. Magnification $\times 25000$. 